GAO

Report to the Ranking Minority Member, Committee on Health, Education, Labor, and Pensions, U.S. Senate

December 2005

\title{
INDIVIDUALS WITH \\ DISABILITIES \\ EDUCATION ACT
}

Education Should

Provide Additional

Guidance to Help

States Smoothly

Transition Children to

Preschool

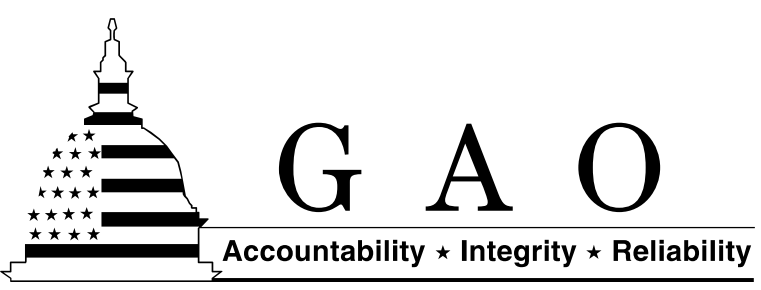




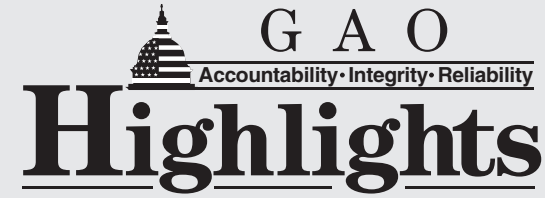

Highlights of GAO-06-26, a report to the Ranking Minority Member, Committee on Health, Education, Labor, and Pensions, U.S. Senate.

\section{Why GAO Did This Study}

Part $\mathrm{C}$ of the Individuals with Disabilities Education Act (IDEA) was established to ensure that infants and toddlers with disabilities, from birth to age 3 , and their families receive appropriate early intervention services. Within the Department of Education (Education), the Office of Special Education Programs (OSEP) is responsible for awarding and monitoring grants to states for Part $\mathrm{C}$ according to IDEA requirements. To address questions about how states have implemented IDEA Part $\mathrm{C}$, this report provides information on (1) how Part C programs differ in their eligibility criteria and whom they serve, (2) to what extent states differ in their provision of services and funding, and (3) how Education and state lead agencies help support and oversee efforts to implement Part $\mathrm{C}$, such as identifying children for services and transitioning children to follow-on programs, such as IDEA Part B.

\section{What GAO Recommends}

GAO recommends that Education provide states with additional guidance on transition planning and services, especially for children who would enter Part B during the summer. In comments on our draft, Education cited an ongoing study of general transition issues. When Education verifies the results of its study, it should use that information to inform guidance to states on transition planning.

www.gao.gov/cgi-bin/getrpt?GAO-06-26.

To view the full product, including the scope and methodology, click on the link above. For more information, contact Marnie Shaul at (202) 512-7215, or shaulm@gao.gov.

\section{INDIVIDUALS WITH DISABILITIES EDUCATION ACT}

\section{Education Should Provide Additional Guidance to Help States Smoothly Transition Children to Preschool}

\section{What GAO Found}

Eligibility criteria for Part C services for infants and toddlers with disabilities differ from state to state, but do not consistently explain the percentage of children served, which ranges between 1.3 and 7.1 percent. To determine eligibility, most states measure how much the child is delayed in one or more areas of early childhood development, while a few rely exclusively on a clinical team's judgment. Although IDEA Part $\mathrm{C}$ is intended to cover children from birth to age 3, most states provide the majority of their Part C services to children 2 to 3 years old. States have public awareness campaigns to identify more eligible infants and toddlers but cite a number of obstacles, including difficulty reaching children in rural areas or in families where English is a second language.

The states we visited provide a similar set of services but vary in funding sources. States are required to make available certain early intervention services under IDEA, such as occupational, physical, and speech therapy. However, states report challenges recruiting and retaining professionals, such as speech language pathologists, to provide these services. States rely on various funding sources, but state general revenue funds were generally the largest source of early intervention funding.

\section{Percentage of Early Intervention Services Most Frequently Provided}

Services



OSEP and state lead agencies have provided training and technical assistance and used data to monitor implementation of IDEA Part C, but OSEP has lacked some information from local officials needed to determine if children are smoothly transitioning from Part C to Part B. OSEP uses annual reports and performance indicators as part of its effort to monitor compliance with Part C and target technical assistance. For example, data on the percentage of children served help inform OSEP of states' efforts to identify all eligible children. States use similar approaches. Despite these activities, state officials cited challenges transitioning children to Part B services when they turn 3 years old. Education indicated that in preliminary and unpublished data from an ongoing study it had found that gaps occur throughout the year. Officials in the states we visited reported that some children who turn 3 during the summer experience gaps in service. If Part B eligibility is not determined prior to children turning 3 during the summer, then subsequent decisions about whether children should receive extended school year services cannot be made. 


\section{Contents}

\section{Letter}

Results in Brief

Background

Eligibility Criteria Differ among States but Are Not Consistently

Related to Percentage of Children Served

Selected States Provide Similar Services but Vary in Funding Sources

Both OSEP and States Use Data to Monitor Part C Compliance, but Challenges Persist in Transitioning Children to Part B 22

Conclusions

Recommendations for Executive Action

Agency Comments and Our Evaluation

\section{Appendix I}

\section{Select Federal and State Funding Sources for Early} Intervention Services

\section{Table}

Table 1: Sources of Funding for Early Intervention Services in Site Visit States

\section{Figures}

Figure 1: States Visited with Type of Agency Leading Part C and Number and Percentage of 0-3 Population Participating in Part C

Figure 2: Stages of a State Early Intervention System from Intake to Service Delivery

Figure 3: National Percentage of Children Receiving IDEA Services by Age in 2004

Figure 4: Examples of Services States Made Available to Infants and Toddlers Covered by Part C 
Figure 5: Percentage of Early Intervention Services Most

Frequently Provided

Figure 6: Examples of Federal and State Funding Sources

\section{Abbreviations}

CDC Centers for Disease Control and Prevention

IDEA Individuals with Disabilities Education Act

IEP

LEA

NEILS

OSEP

individualized education program

TANF

local education agency

National Early Intervention Longitudinal Study

Office of Special Education Programs

Temporary Assistance for Needy Families

This is a work of the U.S. government and is not subject to copyright protection in the United States. It may be reproduced and distributed in its entirety without further permission from GAO. However, because this work may contain copyrighted images or other material, permission from the copyright holder may be necessary if you wish to reproduce this material separately. 
December 14, 2005

The Honorable Edward M. Kennedy

Ranking Minority Member

Committee on Health, Education, Labor, and Pensions

United States Senate

Dear Senator Kennedy:

The first few years of a child's life are critical to development. While most children attain developmental milestones as expected, some children develop more slowly or develop differently because of physical, mental, or environmental factors. Research suggests that for an infant or toddler who exhibits developmental delay, has a diagnosed condition that has a high probability of resulting in developmental delay, or is substantially at risk of having a developmental delay early intervention services, such as family counseling and physical therapy, can have a significant impact on early childhood development. To assist states in ensuring that such infants and toddlers receive early intervention services and support, Congress appropriated $\$ 444$ million in fiscal year 2004 for grants to states under Part $\mathrm{C}$ of the Individuals with Disabilities Education Act (IDEA Part C). States used Part $\mathrm{C}$ grants to arrange early intervention services for approximately 279,000 infants and toddlers with disabilities from birth to age 3 . Administered by the Department of Education's (Education) Office of Special Education Programs (OSEP), Part C is intended to support states' efforts to coordinate and leverage funding from other federal, private, state, and local sources to ensure early intervention services are available to eligible children. For services to children with disabilities after their third birthday, IDEA Part B Section 619 provides grants to states to provide special education and related services to children with disabilities aged 3 through 5 and, at a state's discretion, to children before their third birthday.-

Given your interest in the manner in which states have implemented the provisions of Part C, we examined (1) how Part C programs differ in their eligibility criteria and whom they serve, (2) to what extent states differ in their provision of services and funding, and (3) how Education and state lead agencies help support and oversee efforts to implement Part C, such as identifying children for services and transitioning children to IDEA Part B or other services. 
We used multiple data collection methods to address these issues. We conducted site visits to seven states-Colorado, Hawaii, Illinois, Maryland, Massachusetts, New Jersey, and Oregon-and reviewed their annual performance reports. We chose states to visit based on the type of state agency responsible for coordinating the Part C program (lead agency), number of children served, whether the state served at-risk children, geographic location, and whether the state participated in an OSEP-funded project aimed at early identification of infants and toddlers. Figure 1 illustrates the states visited and selected characteristics. 
Figure 1: States Visited with Type of Agency Leading Part C and Number and Percentage of 0-3 Population Participating in Part C

\section{Site visit states}

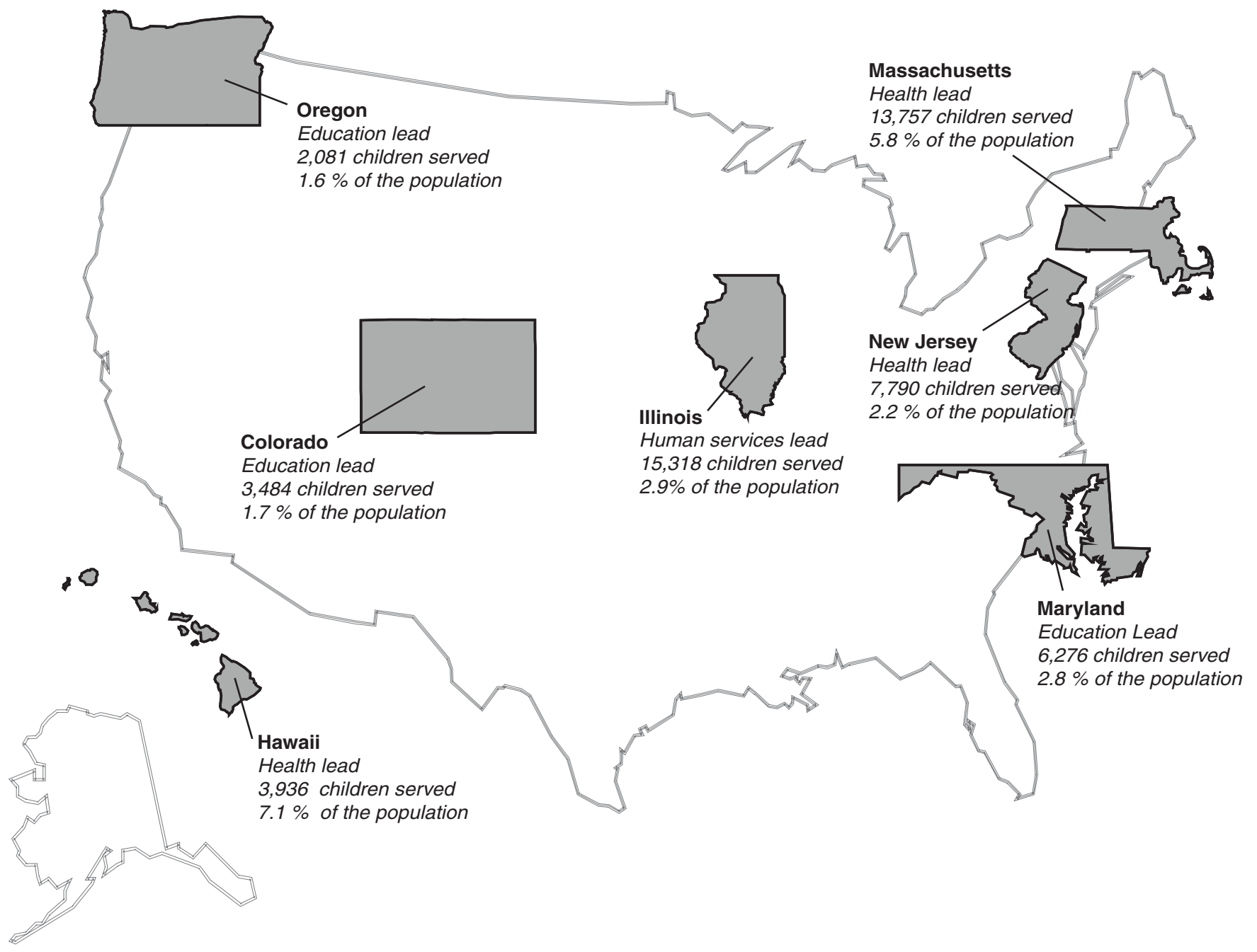

Source: GAO analysis of the Department of Education's 2004 IDEA data, IDEAdata.org, and Office of Special Education Programs Note: Hawaii and Massachusetts serve at-risk children. 
In each of the selected sites, we met with state Part C coordinators, states' Part B staff responsible for transitioning children to preschool programs, and the manager of one or more local early intervention programs. Because Medicaid - the federal-state health-financing program for certain low-income individuals - can be an important source of funds for early intervention services for Medicaid-eligible children, we also met with Medicaid officials in three states. Additionally, we met with OSEP officials and reviewed their guidance and monitoring reports. We also analyzed 2002, 2003, and 2004 data collected by Education. We used the most recent data available from OSEP. These data, available at IDEAdata.org, include information about infants and toddlers with disabilities, such as the services they received, the location where they received them, and what follow-on program they entered when they were no longer eligible for Part C. We used information from IDEAdata.org for the 50 states and the District of Columbia. Although we determined that some data provided by OSEP were not reliable, we obtained documents demonstrating that the office has controls in place to ensure a reasonable degree of accuracy and reliability in many of its data, and determined that the data elements we used were sufficiently reliable for our purposes. We also conducted interviews with educational associations, officials from the Centers for Disease Control and Prevention's National Center on Birth Defects and Developmental Disabilities, and other experts. Our work involved reviewing the availability and differences in types of services; we did not examine the quality of services delivered or the appropriateness of services provided to children. We conducted our work in accordance with generally accepted government auditing standards between September 2004 and December 2005.

Nationwide, states' eligibility criteria for Part C services differ, but are not consistently related to the percentage of children served. State eligibility requirements vary for children who do not have an established or diagnosed condition that has a high probability of resulting in developmental delay. Most states require that such children exhibit a specific level of developmental delay and be deemed eligible according to an informed clinical opinion. A few states rely exclusively on clinical judgment. For example, Arizona requires 50 percent delay in one or more aspects of development, such as physical or emotional, while Hawaii relies on the judgment of a team of clinicians. Moreover, eight states also include in their eligibility criteria infants and toddlers who are at risk of having a substantial developmental delay because of biological risks, such as low birth weight, or environmental risks, such as parental substance abuse. However, eligibility criteria do not sufficiently explain differences in the 
percentage of all infants and toddlers in a state receiving early intervention services. The Centers for Disease Control and Prevention (CDC) reported a lack of data on the prevalence in the general population of children under 3 who have developmental delays and could benefit from early intervention services; many conditions covered by the Part $\mathrm{C}$ eligibility definitions-such as learning disabilities or emotional disorders-are not routinely tracked. Although IDEA Part $\mathrm{C}$ is intended to cover children from birth to age 3, most states (38) provide the majority of their Part C services to children 2 to 3 years old. States have developed public awareness campaigns to help identify more infants and toddlers in need of services, but officials in the states we visited told us that a number of obstacles prevented them from reaching all children as early as possible, including difficulty in reaching children in families where English is a second language or families living in rural areas.

The states we visited provided similar services and confronted similar challenges recruiting and retaining staff to deliver them, but they varied in funding sources. States are required to provide certain services to children in early intervention programs, including occupational, physical, and speech language therapy to help with skills like feeding, walking, and talking. However, states reported challenges recruiting and retaining individuals to provide these services, especially speech language pathologists and occupational therapists. State officials noted that providers often have to spend time traveling to the homes of families to deliver services, which they said could be burdensome, and they also noted salaries are often higher in the private health care sector. States use various sources of funding to support Part $\mathrm{C}$ services, with some relying on multiple funding sources and others relying primarily on Part $\mathrm{C}$ and state general revenue funds. State general revenue funds constituted the largest source of early intervention funding in most of the states we visited, while local funds were often a much smaller source. Officials in the states we visited said there were challenges in accessing some funding sources, such as Medicaid. We found inconsistencies in the funding data states provided to OSEP as part of their annual performance reports, and OSEP decided during our review that the data were incomplete and unreliable and announced plans to stop collecting them.

OSEP and state lead agencies provide training and technical assistance and use data to monitor implementation of IDEA Part C, but they have lacked some information needed from local service providers to determine if children are smoothly transitioning from Part C to Part B. To monitor states' compliance with Part C requirements and to target technical assistance, OSEP examines annual performance reports, performance 
indicators, and other data provided by state lead agencies. States, which are responsible for oversight of local programs, are free to design their own oversight methods, but they generally described approaches similar to OSEP's. Despite oversight and assistance activities, state and local officials in the states we visited cited challenges in transitioning children to Part B services when they turn 3 years old. In addition, in commenting on a draft of this report, Education cited preliminary unpublished data that would suggest transitions are a year-round problem. Officials in the states we visited reported that some children who turn 3 during the summer experience gaps in service during the transition process. The gaps occur, in part, because school districts generally operate on a 9-month academic calendar and some school districts may delay determination of eligibility for any Part B services until the fall. If Part B eligibility is not determined prior to children turning 3 during the summer months, then subsequent decisions regarding extended school year services cannot be made. Most officials said the frequency with which extended school year services are provided to children transitioning to Part B could not be determined because neither OSEP nor the state collected extended school year data. Also, Part $\mathrm{C}$ officials and local early intervention staff told us they face difficulties in finding out if children are determined eligible for Part B. Not having eligibility information hinders local early intervention staff's timely referral of children found ineligible for Part B to other follow-on preschool programs. Additionally, Part C officials are responsible for reporting Part B eligibility to OSEP.

In its comments on a draft of this report, Education disagreed with our recommendation that it incorporate into its research agenda a method for determining how frequently children transitioning from Part $\mathrm{C}$ to Part $\mathrm{B}$ do not receive services during the summer months. Education noted that preliminary and unpublished data from a department study indicate that gaps occur when children are transitioned from Part C to Part B, not only during the summer, but whenever transitions occur. Additionally, in response to our recommendation that if gaps in services are found to be a problem, Education should provide states with additional guidance on improving children's access to extended school year services, Education stated that, based on its preliminary data, there is no need to study extended school year services. We modified our recommendation to acknowledge Education's ongoing study and are now recommending that the Secretary of Education provide states with additional guidance on transition planning and services for children with birthdays during the summer and especially in cases where children are likely to need extended school year services. Additionally, when Education completes and verifies 
the results from its ongoing studies relating to transitioning, it should use that information to inform the department's guidance on transitioning.

According to research, comprehensive early intervention programs can positively affect the progress of children with developmental delays and children at risk of having a disability. Services provided by these programs may include speech language therapy, family counseling, and home visits. Research has linked early intervention services to improvements in toddlers' behavior, interactions between parents and children, infant development, and overall quality of life for children and their families. Additionally, research has found increased mental development and better vocabulary and reasoning skills for children who received early intervention services when compared with those who did not receive these services. Findings from the National Early Intervention Longitudinal Study (NEILS), a research project sponsored by the Department of Education, has found that parents report a high degree of satisfaction after receiving 3 years of early intervention services, reporting that their families are better off and that early intervention services are having "a lot" of impact on their child's development. ${ }^{1}$

IDEA is the primary federal education law for infants, toddlers, children, and youth with disabilities. Grants to states for early intervention services and special education and related services for children with disabilities and their families are provided mainly through Parts C and B of the act. These parts have different histories and are generally administered by different agencies at the state level. IDEA Part $\mathrm{C}$ was established to ensure that infants and toddlers, from birth to age 3 , with disabilities or at risk of developing a disability, and their families receive appropriate early intervention services. Part $\mathrm{C}$ focuses on, among other things, enhancing the development of infants and toddlers with disabilities by providing services in a natural environment, such as the home or a child care center. This part of the law seeks to improve the capacity of the family to meet the child's needs and reduce educational costs by minimizing the need for special education when the child is older. Part B, in contrast, requires that

\footnotetext{
${ }^{1}$ NEILS is tracking the outcomes of over 3,300 infants and toddlers with disabilities and those at risk of a disability and their families. The study tracks children starting from their experiences in early intervention to early elementary school and will provide outcome data on children and families receiving early intervention and how these outcomes relate to child and family characteristics and the types of services provided. The grant for the study ends in 2005 and the final report is anticipated to be available in 2006.
} 
services, to the extent possible, be provided in educational settings, such as regular classrooms. Part B, which includes state grants for children and young adults ages 3 through 21, and Part B Section 619 preschool grants for children 3 through 5 , aims to ensure that children with disabilities have access to a free appropriate public education. Funding for Part B is significantly larger than for Part C programs. In fiscal year 2004, Part C was funded at $\$ 444$ million, and approximately 279,000 infants and toddlers received services. ${ }^{2}$ In contrast, Part B state grants and the Section 619 supplement for preschool services were funded at $\$ 10$ billion and $\$ 388$ million, respectively, in 2004. Approximately 6 million children were provided services under Part B state grants, and over 693,000 children were provided preschool services under Part B Section 619.

To meet Part C goals, states use funds to develop a statewide, coordinated, multidisciplinary, interagency system of early intervention services for infants and toddlers with disabilities and their families. Developing such a system includes designating a lead agency, preparation and dissemination of materials on the availability of services, defining eligibility criteria, and delivering services. To this end, each state has a designated lead agency responsible for the administration, supervision, and monitoring of Part C. In contrast to Part B, which is led by state education departments, Part C is led by the health department in 16 states, education departments in 11 states, and other departments, including combined health and human services departments, in the remaining 23 states. States are expected to leverage funding, services, and resources from other sources to provide early intervention services. Each state must have a continuous process of public awareness activities and evaluations designed to identify and refer as early as possible all young children with disabilities and their families who are in need of early intervention services. By law, public awareness efforts should include disseminating information to parents on available early intervention services and to all primary referral sources, especially hospitals and physicians. Efforts may also include television ads, pamphlets, and posters describing IDEA Part $\mathrm{C}$ and how parents can access services for their child.

Once a child is referred and suspected of having a disability, states are required to conduct an evaluation to determine if the child meets the state's eligibility criteria. In order to be eligible for federal funds under Part C, IDEA requires that states provide services to any child under 3

${ }^{2}$ Part C was appropriated $\$ 441$ million for fiscal year 2005 . 
years of age who is developmentally delayed. These delays must be measured by appropriate diagnostic instruments and procedures or validated by professional opinion, and may occur in one or more of the areas of development-including cognitive, physical, communicative, social or emotional development, and adaptive behavior, such as feeding or toileting. States must also provide services to those children that have a diagnosed mental or physical condition that has a high probability of resulting in developmental delay. However, states are free to define what constitutes a developmental delay and specify how this will be measured. In addition, states may choose to serve children who are at risk of having a substantial developmental delay. These may include biological risks, such as low birth weight, and environmental risks, such as parental substance abuse. Once an eligible delay has been detected, service coordinators work with parents and others to match children with services specific to their needs. Part C requires that every state make certain services available, including special therapies such as physical, occupational, or speech language therapy, and family supports such as home visits. For example, an occupational therapist may come to a child's home to teach a child to draw, which involves hand and eye coordination. The law also requires that services be provided in children's natural environments. Figure 2 illustrates the typical process in early intervention programs. 
Figure 2: Stages of a State Early Intervention System from Intake to Service Delivery

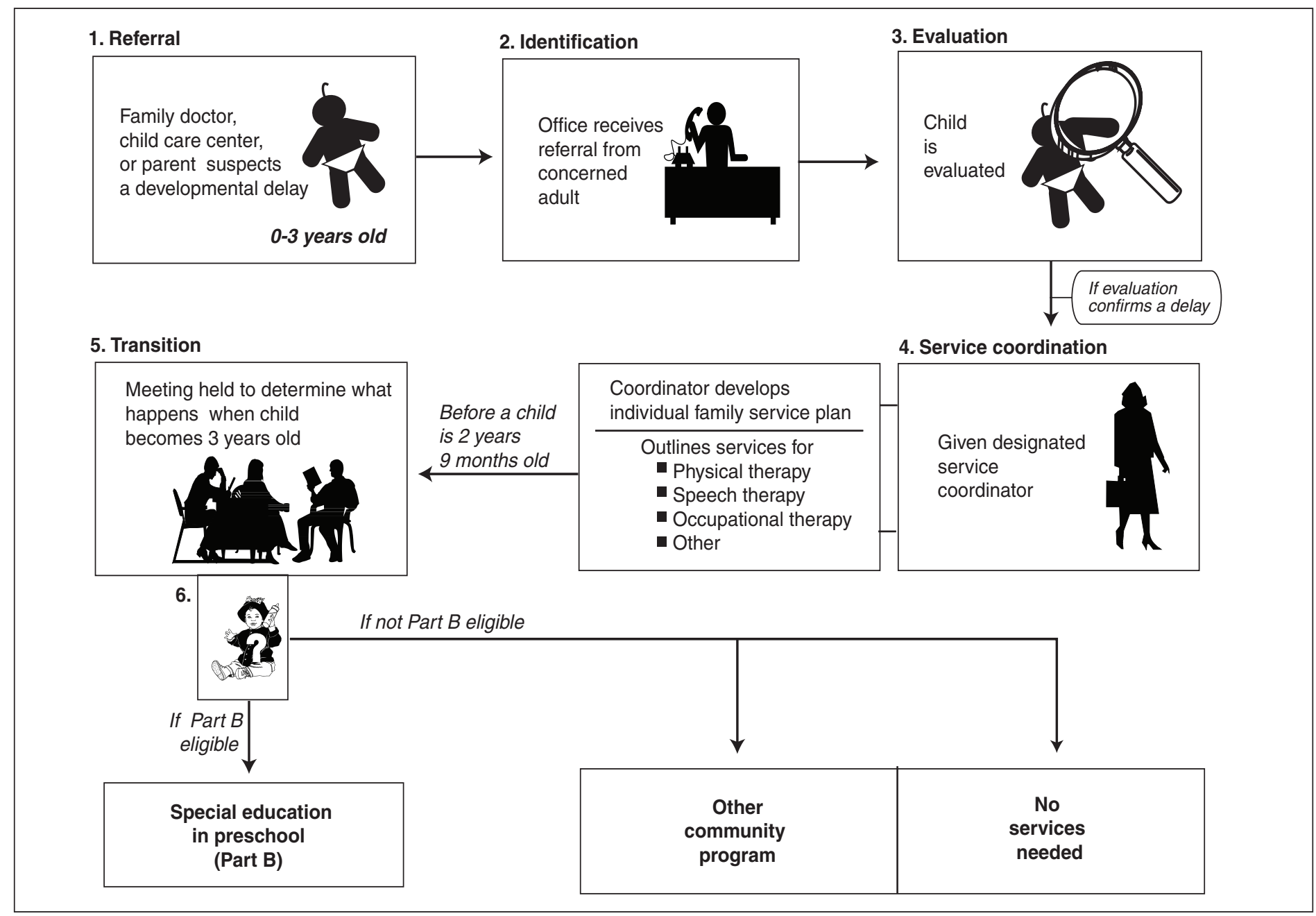

Source: GAO analysis of IDEA Part C legislation.

Children eligible for Part $\mathrm{C}$ can receive early intervention services until they turn 3 years of age. Part $\mathrm{C}$ funds can be used to provide services to children from their third birthday to the beginning of the following school year, but as of 2004 only 14 states have adopted such a policy. Thirty states allow for the use of Section 619 preschool funds to provide services to children before their third birthday. As a child approaches age 3, the local education agency (LEA) determines the child's eligibility for Part B Section 619 preschool services. If eligible for Part B Section 619, the child might also be eligible for extended school year services. An extended 
school year ensures that a child can continue receiving services even when schools are not in session, for example, during the summer. According to Education, most children under Part B do not receive extended school year services. By contrast, Part $\mathrm{C}$ is a year-round program. Eligibility for an extended school year is determined on an individual basis and is generally based on how much a child will regress and the time it will take to regain lost skills. During the most recent reauthorization of IDEA, in 2004, Congress gave states the option of allowing children to continue to receive services under Part $\mathrm{C}$ until they become eligible for kindergarten.

Eligibility Criteria Differ among States but Are Not Consistently Related to Percentage of Children Served
States vary in both the criteria used to establish eligibility for services and the means used to assess whether children fit these criteria, but these differences are not consistently related to the percentage of children receiving early intervention services. While Part $\mathrm{C}$ is intended to serve infants and toddlers from birth to age 3, the majority of children receiving services nationwide and in most states are toddlers between ages 2 and 3 . Officials in states we visited told us that despite their various public awareness efforts, there are a number of challenges in identifying all children eligible for services, specifically reaching children whose families speak limited English or live in rural areas. Comprehensive data on the number of children who could benefit from early intervention are not available; many conditions covered by Part C—-such as emotional disorders and learning disabilities-are not systematically tracked.
States Have Different Eligibility Criteria and Means of Assessing Developmental Delay
Nationwide, states' eligibility criteria for Part C services vary, with most states specifying the amount of delay in development a child must experience to be eligible for services, while a few rely exclusively on the judgment of a multidisciplinary clinical team. IDEA generally gives states the discretion to determine specific eligibility criteria and diagnostic procedures. For example, Part $\mathrm{C}$ specifies that a child have an established condition that has a high probability of resulting in a developmental delay, or that a delay is present in one or more areas of development-cognitive, physical, communicative, social or emotional, or adaptive-and that all states allow for the use of informed clinical opinion in their evaluation. However, states can determine the amount of delay a child must experience in order to be eligible for services. Part $\mathrm{C}$ also gives states discretion to identify the appropriate diagnostic instruments to measure the extent of a child's delay or to rely exclusively on the informed opinion of professionals. For example, Arizona requires a 50 percent delay in one or more aspects of early childhood development, such as physical or emotional development. New Jersey's eligibility criteria vary depending on 
the number of areas in which a child is developmentally delayed. The state requires that children have a 33 percent delay in one area of development, but a 25 percent delay in two or more areas of development. The Centers for Disease Control and Prevention noted that the significance and implication of a given percentage delay vary across areas of development. For instance, according to CDC, a 25 percent delay in motor skills development has much different implications for services for a child than a 25 percent delay in language development. Other states' eligibility criteria are based on the number of months or standard deviations from age norms. For example, in Massachusetts, a 24-month-old child functioning at an 18-month-old level could be eligible for services. In Georgia, a child whose cognitive abilities are at least two standard deviations less than the abilities of most children at the same age would be eligible for services. Hawaii does not specify a percentage delay and instead relies on the judgment of a multidisciplinary team, which generally includes either a speech therapist or special educator and an occupational or physical therapist. Despite wide variation in how states define eligibility, variation among states in the percentage of children served is not consistently explained by eligibility criteria. For example, Alabama, which has broad eligibility criteria (25 percent delay in one or more areas) served only 1.3 percent of infants and toddlers in 2004, while North Dakota, which has stricter eligibility criteria (50 percent delay in one area, 25 percent delay in two or more areas, informed clinical opinion), served 2.8 percent of its infants and toddlers. In 2004 the percentage of children served from state to state ranged between 1.3 and 7.1 percent.

Although not required by Part C, as of March 2005, 8 states-California, Hawaii, Indiana, Massachusetts, New Hampshire, New Mexico, North Carolina, and West Virginia-also served children at risk of having a substantial developmental delay. For example, in Hawaii, children from families where child abuse or neglect is present may qualify for services. In Massachusetts, children born with low birth weight or chronic lung disease may qualify for services. States that we visited that do not serve atrisk children-Colorado, Illinois, Maryland, New Jersey, and Oregonexpressed interest in serving them but told us that the additional costs associated with increasing the number of eligible children prevented them from doing so. Instead of providing services to at-risk infants and toddlers under IDEA Part C, some states track at-risk children or provide services to them through other programs. For instance, in Ohio, children at risk are served through a statewide program, funded in part by federal dollars, known as Ohio Early Start. Through this program, they receive services similar to those children receive under Part C. 
Majority of Children Served under Part C Are between Ages 2 and 3
While Part $\mathrm{C}$ funding is intended to serve infants and toddlers from birth to age 3 , the majority of children receiving services are toddlers between ages 2 and 3. In 2004, infants, children under the age of 1, constituted only 14 percent of the approximately 279,000 children served nationwide, and 2 to 3-year-olds accounted for 54 percent. Likewise, in 38 states, the majority of children served were 2 to 3 -year-olds. In Maryland and Illinois, 2 to 3year-olds made up 54 percent and 55 percent of the children served, respectively. OSEP and state officials told us that a majority of children enter the Part $\mathrm{C}$ system after age 2 because this is the age at which speech language delays become apparent and indicated that such deficiencies are not easily detected in younger children. According to Education officials, difficulty detecting deficiencies in younger children is due to numerous factors, including difficulties in assessment, pediatrician or parent "wait and see" attitudes, and lack of parental consent. Children who enter the Part C program in infancy are generally those diagnosed at birth with conditions such as chromosomal abnormalities and genetic or congenital disorders.

It also appears that many children are eventually identified as needing services when they become older. Part B Section 619, which serves children ages 3 through 5 years, serves many more children than Part C, as shown in figure 3. In 2004, Section 619 served over 693,000 children, compared with approximately 279,000 children under Part C, and this pattern is mirrored in most states. This may be attributable to a variety of factors. Some delays become more apparent as children get older. Developmental delays are also more likely to be detected once a child enters a group setting, such as a preschool or kindergarten program, when comparison with peers may highlight some delays. Additionally, some parents may turn to private insurance to pay for services during the first few years of a child's life, and enter the IDEA system when their child enrolls in a formal education program at ages 3, 4, or 5. However, Massachusetts and Hawaii serve at least the same number of children in their Part C programs as they do in their Part B Section 619 programs. Both states include at-risk children in their Part C eligibility criteria. 
Figure 3: National Percentage of Children Receiving IDEA Services by Age in 2004



States Face Challenges in Identifying All Children Eligible for Services
Officials in the 7 states we visited told us that a number of obstacles prevented them from reaching all children, even though all of these states, as required by law, had developed public awareness campaigns to help identify infants and toddlers in need of services. To inform the public of the program, states used television, radio, and newspaper ads; presentations at community fairs; and distribution of pamphlets and brochures at doctors' offices, hospitals, and other appropriate locations. For example, in one of the sites we visited, posters were developed to hang in doctors' offices across the state to help inform parents about Part C.

Despite their public awareness campaigns, the states we visited reported having difficulty reaching all eligible children. Officials noted that it can be especially difficult to reach families for which English is a second language. While some states we visited produced public awareness materials in Spanish, they had not expanded their efforts to include materials in other languages. Officials also told us that it can be hard to reach families who live in rural areas because they may visit a pediatrician less frequently because of the long distance they must travel to get to the doctor. While officials in 6 of the 7 states we visited noted that physicians 
were the principal source of referrals, they also told us that they believed physicians were hesitant to make referrals to Part $\mathrm{C}$ programs because of a fear of misdiagnosing a child with a disability. They believed that a misdiagnosis could cause unnecessary anxiety in a parent whose child is developing more slowly but would eventually begin to demonstrate ageappropriate skills without needing early intervention services.

Additionally, the American Academy of Pediatrics found through its own studies that a lack of understanding of the early intervention program's processes and procedures is a barrier to physicians' referring children.

Selected States

Provide Similar

Services but Vary in Funding Sources
States provide a broad array of early intervention services to eligible children and face similar challenges in recruiting and retaining staff to provide these services, but they vary in the sources of funding they draw from. States provide a wide range of medical and educational services to children and their families and rely on professionals, including occupational therapists, physical therapists, and speech language pathologists, to deliver these services. Yet officials in the states we visited reported that they are finding it increasingly difficult to recruit and retain these individuals. To fund early intervention services for children from birth to age 3 , states relied on funding from multiple sources, including federal, state, and private funding. However, some states reported difficulties accessing certain types of funding, such as Medicaid.
States Provided a Broad Array of Services to Infants and Toddlers, but States We Visited Reported Challenges Recruiting and Retaining Staff
As required under Part C, states provide a broad array of early intervention services to infants and toddlers. Under Part C, infants and toddlers with a disability are entitled to receive an evaluation of their strengths and needs, service coordination, and support for a smooth transition from early intervention to preschool programs. In addition, children receive individualized services that may include physical therapy, family counseling, and nutrition services. States, as required by law, reported making all services shown in figure 4 available to infants and toddlers. 
Figure 4: Examples of Services States Made Available to Infants and Toddlers Covered by Part C

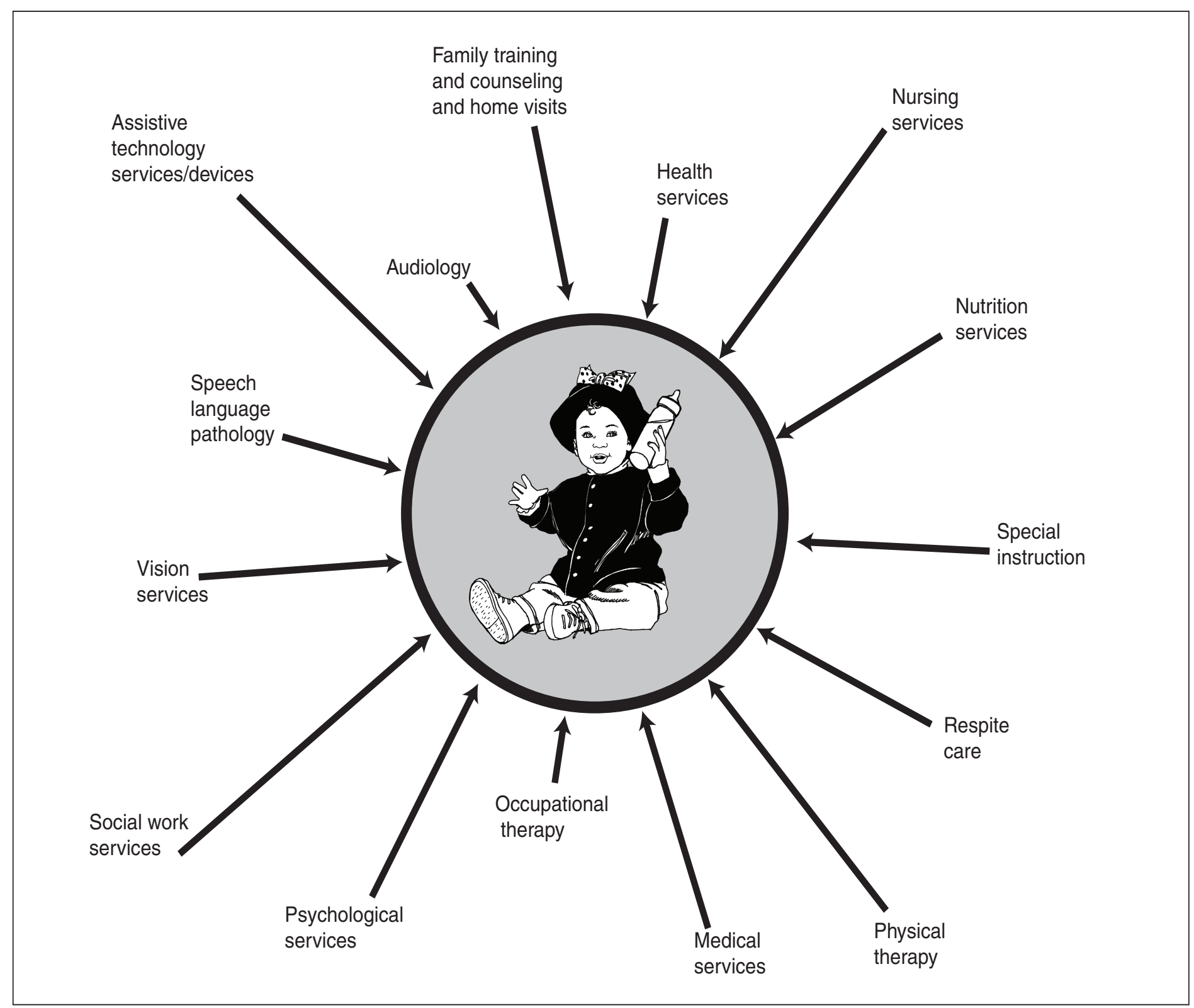

Source: GAO analysis of U.S. Department of Education's 2002 IDEA database.

Figure 5 shows that the most frequently received services nationwide are speech language therapy, special instruction, physical therapy, and occupational therapy. Psychological and nutrition services were among 
the least frequently provided. The states we visited were similar in their mix of services. For example, in states such as Maryland, Oregon, and Colorado, speech language, physical, and occupational therapy, to help with skills like feeding, walking, and talking, were the most frequently provided services, and services such as psychological services and nutrition services were rarely provided.

\section{Figure 5: Percentage of Early Intervention Services Most Frequently Provided}

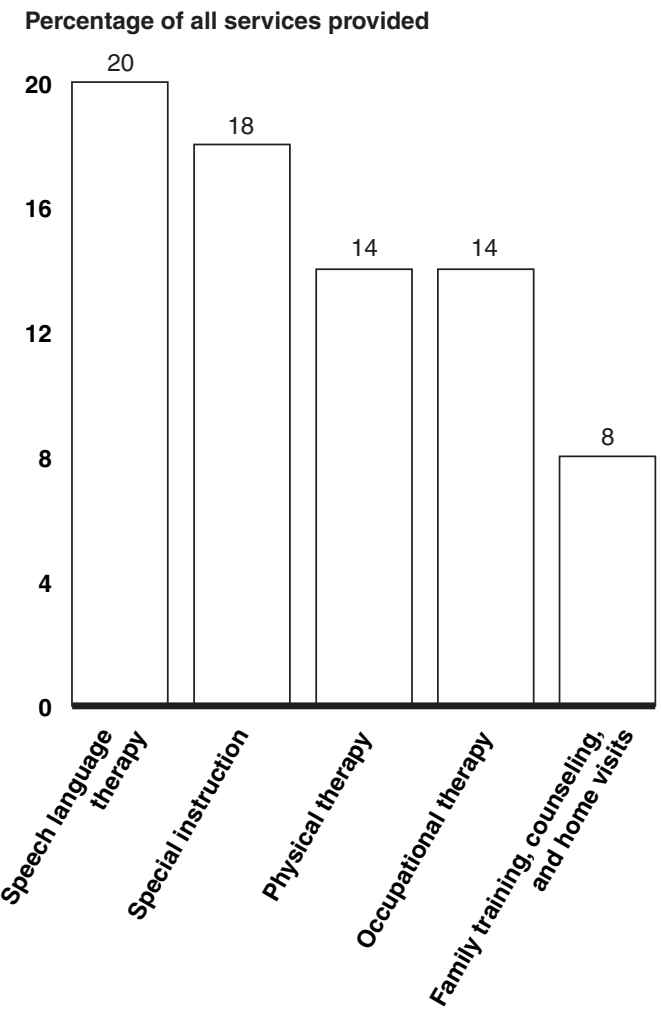

Services

Source: GAO analysis of the Department of Education's 2002 IDEA data, IDEAdata.org.

These services were provided in a variety of settings, including the home, hospital, and day care, and through public and private service providers. For instance, according to Maryland officials, LEAs, departments of health, and departments of human services in the state provide services to infants and toddlers in addition to private providers. In Massachusetts, a network of private programs provides early intervention services under contract with the state. 
Officials in each of the states we visited reported challenges in recruiting and retaining staff to provide early intervention services. Specifically, speech language pathologist and occupational therapist were the most difficult positions to fill. Officials cited several reasons for these challenges. Early intervention staff are required by Part $\mathrm{C}$ to serve children in natural environments, such as homes or child care centers. This requires staff to travel to these locations, which can be time-consuming and costly. For instance, in Hawaii, state officials told us that it is hard to schedule services for children in neighboring islands because of the long travel times to reach them. Additionally, state officials told us that salaries earned by early intervention contractors were not always competitive with salaries and benefits available in the private health care sector. These challenges make it difficult for some early intervention programs to hire professional staff. Understaffed programs can often result in heavier caseloads in which children do not receive services or receive services less often than intended.

States Use Various Funding Sources in Addition to Part C, but Selected States Report Difficulties Accessing Funds
To help pay for services for infants and toddlers, states draw on a range of federal, state, and local funding sources. As shown in figure 6 , states accessed funds from a variety of sources at the federal level, including the Child Care and Development Block Grant, IDEA Part B, and Medicaid, and from the state level. See appendix I for a glossary of these federal and state funding sources. 
Figure 6: Examples of Federal and State Funding Sources

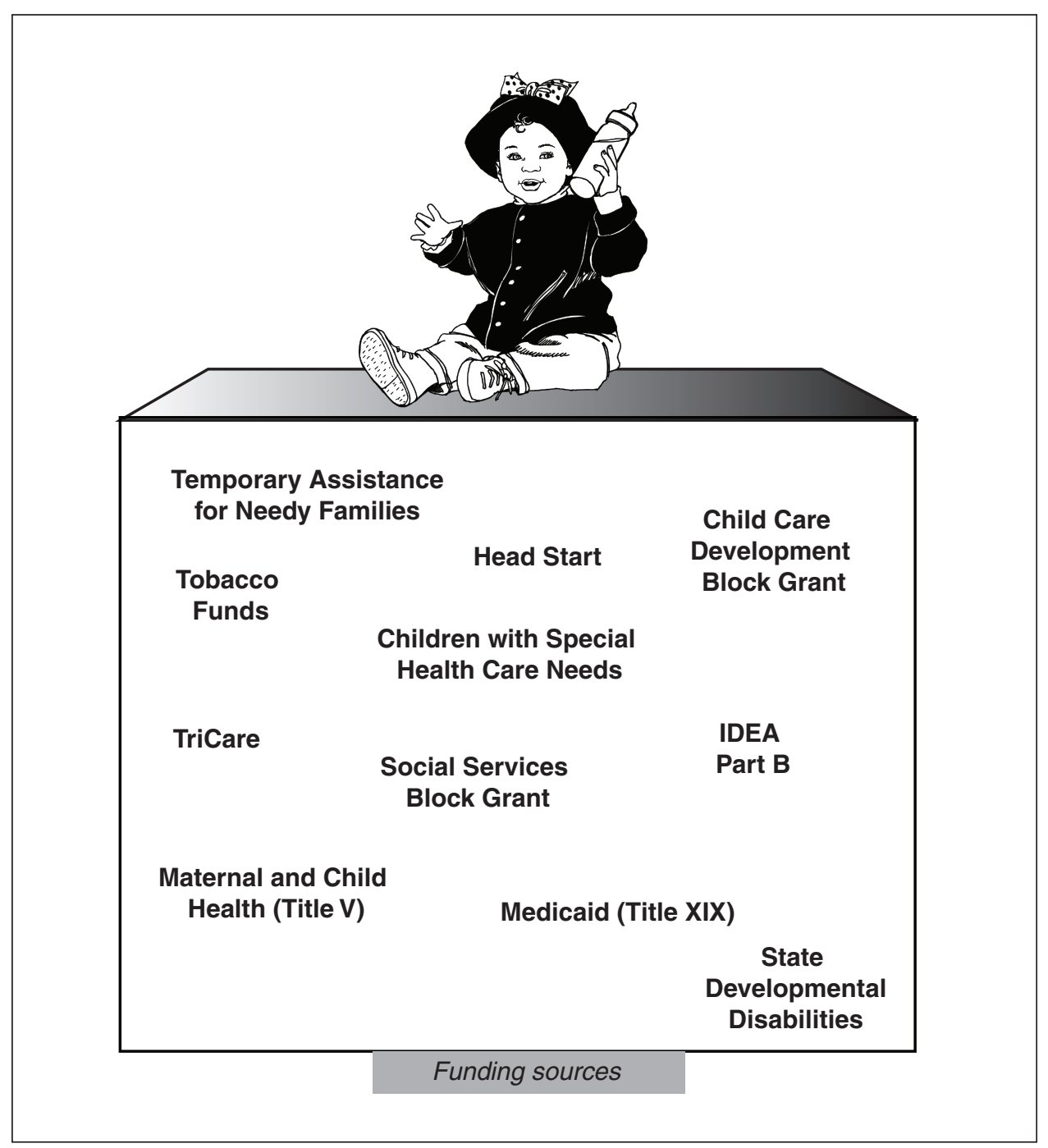

Source: 2003 state annual performance report data from OSEP.

State general revenue funds represent the most frequently used funds by states after federal Part C dollars. All 50 states reported using state general funds.

For most states we visited, local support represented a small proportion of reported early intervention funding, but in one-Maryland-it accounted for 51 percent. However, states did report receiving funds from local sources or through private insurance and fees collected from a child's 
family. For example, New Jersey charges a sliding monthly fee based on family size and income relative to federal poverty guidelines. State officials said families that can afford to contribute to the cost of service provision do so, but families that cannot afford the fee still receive services. In fiscal year 2003, New Jersey collected $\$ 43,862$ in revenue from this fee, which made up less than 1 percent of its reported early intervention service funding.

In 4 of the 7 states we visited, states provided most of the funding for services for infants and toddlers, and Part $\mathrm{C}$ represented a smaller percentage of total funding. For example, in Illinois, state general revenue funds represented 57 percent of the total funding reported for infants and toddlers with disabilities, and Part $\mathrm{C}$ funds represented 17 percent. However, Part $\mathrm{C}$ represented a larger percentage of reported funding in certain states. For instance, in Colorado, Part C funds made up 38 percent of funds reported for infants and toddlers with disabilities. See table 1 for funding sources in the states we visited.

Table 1: Sources of Funding for Early Intervention Services in Site Visit States

\begin{tabular}{|c|c|c|c|c|c|c|c|}
\hline \multicolumn{8}{|c|}{ (Dollars in millions) } \\
\hline & Part C & Other federal & Medicaid & $\begin{array}{r}\text { State general } \\
\text { revenue }\end{array}$ & Other state & $\begin{array}{r}\text { Private } \\
\text { insurance/fees }\end{array}$ & Local support \\
\hline Colorado & $\$ 6.10$ & $\$ 0.00$ & $\$ 3.10$ & $\$ 6.80$ & $\$ 0.00$ & $\$ 0.00$ & $\$ 0.00$ \\
\hline Hawaii $^{a}$ & $\$ 2.00$ & $\$ 0.19$ & $\$ 0.02$ & $\$ 8.00$ & $\$ 0.01$ & $\$ 0.00$ & $\$ 0.41$ \\
\hline Illinois & $\$ 15.20$ & $\$ 0.00$ & $\$ 15.20$ & $\$ 49.70$ & $\$ 0.00$ & $\$ 6.20$ & $\$ 0.00$ \\
\hline Maryland & $\$ 7.60$ & $\$ 4.70$ & $\$ 1.80$ & $\$ 5.20$ & $\$ 2.30$ & $\$ 0.01$ & $\$ 23.20$ \\
\hline Massachusetts & $\$ 8.40$ & $\$ 0.21$ & $\$ 19.40$ & $\$ 29.90$ & $\$ 0.00$ & $\$ 32.20$ & $\$ 0.00$ \\
\hline New Jersey & $\$ 13.70$ & $\$ 0.50$ & $\$ 4.40$ & $\$ 40.60$ & $\$ 1.00$ & $\$ 0.04$ & $\$ 5.20$ \\
\hline Oregon $^{b}$ & $\$ 4.50$ & $\$ 0.00$ & $\$ 2.10$ & $\$ 8.00$ & $\$ 1.80$ & $\$ 0.00$ & $\$ 0.00$ \\
\hline
\end{tabular}

Source: GAO analysis of fiscal year 2003 data provided by state officials.

${ }^{a}$ Funding data for Hawaii are incomplete, as the state does not include data from its Public Health Nursing Branch and Healthy Start programs.

'Oregon's Medicaid data are for both Part B and Part C; the state does not separate the two programs.

Beyond our collection of funding data in our seven site visits, we looked at funding data for all 50 states by examining the information states provided to OSEP as part of their annual performance reports. Their data included federal, state, and local funding sources, as well as the dollar amounts for each. However, during the course of our review, we found that data were incomplete. For instance, Hawaii did not report funding for two programs 
that provide early intervention services. We found similar gaps in examining funding data reported to OSEP by additional states. ${ }^{3}$ During the course of our review, OSEP concluded the funding data from states were unreliable and announced plans to stop collecting such data.

States we visited reported challenges in accessing certain funding sources. For some smaller programs and funding sources, officials in some states we visited said the paperwork was too cumbersome for the small amount of funding they might receive in return. In other cases, some officials reported difficulty obtaining Medicaid reimbursement for Part C services. In Oregon, where the state department of education is the lead agency, officials explained that the different terminology educators use to describe certain needed services makes it hard to access Medicaid for early intervention services. For instance, Medicaid may pay for occupational therapy if the purpose is health-related in nature-such as teaching a child to eat. But Medicaid may not provide reimbursement if the stated purpose of the therapy appears educational, such as teaching a child to grasp a crayon to draw. ${ }^{4}$ Despite the challenges some states reported, Massachusetts officials cited a strong and collaborative working relationship with Medicaid and private insurance. For example, since 1985, the state has had operational standards that include reimbursement of virtually all Part C services through Medicaid.

\footnotetext{
${ }^{3}$ A 2004 expenditure study, conducted as part of the National Early Intervention Longitudinal Study, concluded that early intervention programs use a blend of federal, state, and local funding to provide early intervention services, but that while programs could report sources of funding, they had difficulty reporting precise amounts of funding or breaking down the revenues by sources.

${ }^{4}$ We earlier reported challenges in coordinating Medicaid and IDEA for school-aged children. See GAO, Medicaid and Special Education: Coordination of Services for Children with Disabilities Is Evolving, GAO/HEHS-00-20 (Washington, D.C.: Dec. 10, 1999).
} 
Both OSEP and States Use Data to Monitor Part C Compliance, but Challenges Persist in Transitioning Children to Part B
OSEP monitors the states, which in turn oversee local Part C programs by examining data on how well programs identify, serve, and transition children to other programs when they are too old for Part C. In its oversight, OSEP tracks data on program performance submitted by states through annual performance reports and other mechanisms. As part of its efforts, OSEP uses two key performance indicators-percentage of infants and toddlers receiving early intervention services and the percentage of these children receiving services in natural environments- to target site visits and technical assistance to programs most in need of guidance. States oversee Part C in similar ways but are free, within certain parameters, to design their own oversight strategies. Although federal and state data and oversight efforts have helped identify some performance problems, challenges remain in transitioning children from Part $\mathrm{C}$ to Part B Section 619 and other follow-on preschool programs. In 5 of the 7 states we visited, officials said that some children who turn 3 during the summer and are eligible for Part B preschool experience service gaps when school is not in session. OSEP does not have data on how frequently children are provided extended year services during the summer months.
OSEP Monitors and Supports Implementation of Part C by Tracking Key Data
To ensure that programs are managed well and that eligible infants and toddlers receive the services they need, OSEP monitors the states by collecting and tracking key data. Specifically, each state submits an annual performance report to OSEP, which includes a narrative on five areas of program performance and plans for improvement. States report on (1) what they are doing to identify children and the effectiveness of these efforts; (2) how well they are helping families develop the skills they need to help their children; (3) whether services are provided to children in a natural environment, such as, home, day care, or other programs for typically developing children; (4) whether transition planning is available to children and their families; and (5) what they are doing to supervise and manage local programs. States report on progress or challenges in meeting performance goals and state-developed indicators as well as projected timelines, activities, and resources needed to achieve future targets. For example, with respect to identifying all children eligible for services, Illinois set a goal for the period covering July 2003 to June 2004 to increase the percentage of children receiving early intervention services to 2.6 percent of all children and to screen 200,000 children for developmental delays, approximately 37 percent of the state's population age 0 to 3 . In its annual performance report for that period, Illinois described the strategies it used to exceed its participation target-2.76 percent of children received services-and explained why it fell 58,000 children short of its target for screenings. 
In addition to information submitted as part of the annual performance reports, states also report data to OSEP in five areas: (1) number and percentage of children receiving services, (2) the specific settings in which children receive services, (3) number of children who stopped receiving Part C services and the reason for stopping, (4) number and types of services provided, and (5) the number of clinical personnel employed or contracted to provide services. IDEA requires states to submit data in the first three areas, and OSEP, under authority granted to it in IDEA, requires states to submit data in the final two areas. For future reporting periods OSEP plans to discontinue collection of personnel data because they were found to be unreliable. Additionally, OSEP will stop collecting information about the number and types of services provided. The reporting data complement and inform topics covered in the annual performance reports.

\section{Failure to Reach a Key Child Identification Indicator Can Signal Part C Compliance Problems}

OSEP uses the annual performance reports and other reporting data to identify problem areas and target its oversight efforts. In particular, OSEP compares states against the national average on two performance indicators: (1) the percentage of all infants and toddlers in the state receiving early intervention services, which was 2.2 percent as of 2003 , and (2) the percentage of infants and toddlers with disabilities receiving early intervention services in a natural environment, which was 83 percent, as of 2002. ${ }^{5}$ These indicators were developed by OSEP with input from interested parties, including states and the Centers for Disease Control and Prevention. ${ }^{6}$ OSEP officials said they chose these indicators because of their confidence in the accuracy of the data and because they are closely linked to other Part $\mathrm{C}$ requirements. OSEP considers whether

\footnotetext{
${ }^{5}$ The national average for the percentage of all infants and toddlers receiving early intervention services is calculated based on the birth to age 3 population receiving early intervention services on December 1 divided by the total number of children ages 0 to 3 on that date. In 2004, 2.3 percent of the nation's infants and toddlers received early intervention services. The national average for the percentage of infants and toddlers with disabilities receiving early intervention services in natural environments is calculated based on the number of children receiving services in a natural environment (homes and programs for typically developing children) divided by the total number of children receiving services in all settings.

${ }^{6}$ An initial baseline performance goal of serving 2 percent of states' population ages 0 to 3 was based on conditions under observation by the Centers for Disease Control through the Metropolitan Atlanta Developmental Disabilities Study. These observations did not include certain conditions covered by Part $\mathrm{C}$ that are difficult to detect in young children, such as learning disabilities and behavioral and social/emotional problems.
} 
states have fallen below the national average when deciding whether to target states for technical assistance and closer monitoring. In 2003, half of all states served less than 2.2 percent of children. OSEP officials note that the indicators do not directly measure compliance with Part C, but they serve as an early warning signal that states may need assistance.

OSEP relies on the first performance indicator as a measure of the level of access states are providing for early interventions and the success of efforts to identify all eligible children. It has collected this performance information since at least 1996, and the percentage of the nation's children between birth and age 3 receiving services has steadily increased since 1998-from 1.6 percent to 2.2 percent in 2003. Twenty-five states met or exceeded this indicator in 2003. Of these 25 states, 7 served between 3.4 and 7.7 percent. The fact that half of all states served 2.2 or more percent, and some served as high as 7.7 percent, combined with the known difficulties in reaching all eligible children, suggests that the actual eligible population may be larger than the number of children states are identifying. The Centers for Disease Control and Prevention told us that comprehensive data on the number of children who could benefit from early intervention are not available.

OSEP pays particular attention to states that do not meet its performance indicator. Failure to meet this indicator can be a signal that the state is not doing enough to identify all eligible children and raise public awareness of available early intervention services. First, OSEP might encourage these states to seek help from technical assistance centers or OSEP staff. States can get technical assistance on an ongoing basis through several vehicles, such as conferences, six regional centers, research and training centers, and a national center. Second, OSEP might schedule a site visit, at which it would interview state and local officials, providers, and parents and review program data in more depth. After OSEP completes a site visit, it prepares a monitoring report addressing strengths and areas of noncompliance with Part C.

Using data from annual performance reports and site visits, OSEP has found states out of compliance with Part $\mathrm{C}$ for a number of issues related to the goal of identifying all eligible infants and toddlers for services. OSEP finds states out of compliance for, among other reasons, not making adequate public awareness efforts to inform culturally diverse groups about available early intervention services, not disseminating public awareness materials to pediatricians and other referral sources in rural areas, not referring children from underrepresented groups for services in a timely manner, and not carrying out service coordination 
responsibilities. Between July 1, 2002, and June 30, 2003, 14 states were found out of compliance with child identification requirements. These states served 0.9 to 7.7 percent of their population, with 9 of the 14 states serving less than 2.2 percent of their population. OSEP found Nevada (which was the state that served the lowest percentage of infants and toddlers at 0.9 percent in 2003) out of compliance for not ensuring that all children who may be eligible for early intervention services are identified, located, referred, and evaluated in accordance with Part C. Hawaii, which serves the largest percentage of children, including children at risk of having a substantial developmental delay, was found out of compliance because it lacked procedures to ensure evaluations and assessments were conducted in all the areas required by Part C.

When states are not in compliance with Part $\mathrm{C}$ and do not show improvement in their performance, even after receiving technical assistance, OSEP has several options. Initially, OSEP might work with a state on a plan of corrective action with a timeline, or issue a letter to the state documenting the specific problems. As a last resort, OSEP can impose formal sanctions against a state, including withholding funds, referring the matter to the Department of Justice, entering into a voluntary compliance agreement with a state and its respective lead agency that sets a timeline for bringing the state into compliance, and incorporating special conditions into a state's grant award. OSEP reports that it rarely withholds funds or refers any noncompliance issues for Part $\mathrm{C}$ programs to the Department of Justice. Two states, South Carolina and Arizona, are currently on compliance agreements, and several have special conditions in their grant awards. ${ }^{7}$

OSEP is using its second performance indicator, on the percentage of infants and toddlers with disabilities receiving early intervention services in a natural environment, in the same way it uses data about the percentage of all infants and toddlers in the state receiving early intervention services. OSEP officials told us that on the basis of provisions in the 2004 reauthorization of IDEA, they recently developed a new set of performance indicators. States will submit to OSEP baseline data on these measures in December 2005. The new indicators generally build upon data currently being collected to look in new ways at how states provide early

\footnotetext{
${ }^{7}$ For additional information on OSEP's efforts to address issues of noncompliance under Part B of IDEA see GAO, Special Education: Improved Timelines and Better Use of Enforcement Actions Could Strengthen Education's Monitoring System, GAO-04-879 (Washington, D.C.: Sept. 9, 2004).
} 
intervention services in a natural environment, identify children, transition children to follow-on services, and address supervision and management issues. For example, the new indicators for identifying children include a comparison of the percentage of children served in each state with the average in other states with similar eligibility criteria, and information about the percentage of children who proceeded through the evaluation, assessment, and service planning stages of the early intervention system according to timelines required by Part C. Similarly, the new transitioning indicators require information about the percentage of children who receive timely transition planning.

States Have Responsibility for Oversight of Local Early Intervention Providers
State lead agencies play a critical role in monitoring and supporting early intervention services through their responsibility for local Part C programs. Instead of directly providing services to infants and toddlers with developmental delays, in the states we visited, local and regional early intervention programs generally deliver and coordinate services. The states, then, are responsible for ensuring the local programs are in compliance with Part C. States use many of the same approaches as OSEP in monitoring and supporting local programs, such as file reviews, reporting requirements, program certification or funding awards, employing training and technical assistance staff, and monitoring visits. States frequently interact with local early intervention programs. For example, Massachusetts officials seek to visit half of their 63 local programs each year.

OSEP encourages collection of outcome data from parents and is sponsoring research on outcomes, which is scheduled to be completed in 2006. At least 4 of the states we visited monitor early intervention services by conducting parent surveys. The surveys measure parental satisfaction with the delivery of early intervention services, how well parents feel services are coordinated, and parents' experiences working with staff to transition their children to follow-on services. OSEP provides funding for technical assistance to help states develop parent surveys. These survey data and information from OSEP's National Early Intervention Longitudinal Study are potential sources of outcome data about early intervention services. Additionally, the Early Childhood Outcomes Center, a 5-year project funded by OSEP, is providing technical assistance to support states in developing and implementing other outcome measurement systems for children with disabilities. The Early Childhood Outcomes Center is attempting to develop outcome data that can be aggregated at the national level, document program effects, and improve programs at the local and state levels. 
State Part C officials we spoke with explained that they have to hold local early intervention programs accountable for the same performance indicators for which OSEP holds them accountable. As with OSEP, state Part C coordinators have taken actions to enforce compliance with IDEA. Officials in Colorado said they had taken away funding from programs that failed to comply with Part $\mathrm{C}$ requirements. Also, when states fail to enforce IDEA requirements, they risk not only being found in noncompliance, but also lawsuits brought by individuals under IDEA. Such was the case in Hawaii and Illinois. In Hawaii, parents and mental health advocates alleged that qualified handicapped children were not receiving mental health services. In Illinois, plaintiffs alleged that the state had a waiting list for children who were eligible for services. Both states settled the lawsuits by agreeing to take specific steps to come into compliance with the act.

Overseeing and Coordinating Transitions to Part B Remains a Challenge
Although the information that OSEP and the states compile has helped identify some performance problems, overseeing and coordinating children's transitions to IDEA Part B remains a challenge. The transition process involves several sequential steps, and when any of these steps are delayed, a child could miss out on critical services and providers can be left without important information on a child's status. As a child nears age 3 , local early intervention staff must inform the child's family about followon programs that may be available for the child, such as Part B Section 619. Local early intervention staff, with the approval of the family, hold a conference with the family and, if the child is potentially eligible under Part B, LEA officials, to discuss any services the child may be eligible to receive. This transition planning conference for children potentially eligible under Part B, must occur at least 90 days before the child's third birthday. Early intervention staff and the family must develop a written transition plan. And if the child is believed eligible for Part B services, early intervention staff must notify the LEA. The LEA must determine the child's eligibility within a reasonable time frame, and if the child is found eligible, a meeting to develop an individualized education program (IEP) for the child must be conducted within 30 days. Part B requires teachers, parents, school administrators, and related services personnel to develop the IEP shortly after a child is found eligible for Part B services, and the IEP guides the delivery of special education supports and services for a student with disabilities.

While IDEA requires states and local programs to provide transition planning and follow these specific procedures, we found in our site visits that delays still happen. Education cited preliminary unpublished data that 
would suggest transitions are a year-round problem. We found that delays generally occur for two reasons. First, data in annual performance reports indicate that some states have difficulty scheduling transition meetings 90 days in advance of a child's third birthday. State and local officials we interviewed said it was difficult to assemble all of the requisite individuals for the conference before the deadline. Second, some state officials expressed concern about the timing of the LEA's decision on a child's eligibility. The decision may be delayed until the following school year for children with summer birthdays because LEAs generally operate on a 9- or 10-month academic calendar. In 5 of the 7 states we visited, officials said that some children who turn 3 during the summer and are eligible for Part B preschool experience service gaps when school is not in session. As a result of these delays in the transition process, some children who need extended school year services during the summer may not receive them. Most of the states we visited do not keep track of the number of eligible children who do or do not receive extended school year services.

There are two potential ways to ensure children do not experience gaps in services. First, extending Part $\mathrm{C}$ services until children are eligible to enter kindergarten, which was permitted for the first time with the reauthorization of IDEA in 2004, could mitigate some of the challenges associated with transitioning children. However, none of the states we visited plan to exercise this option. States indicated that it would be too costly for them to extend Part C service and that Part B officials are not willing to support doing so with Part B Section 619 funds. Second, Part C funds can be used to provide services to children from their third birthday to the beginning of the following school year, but an OSEP technical assistance center reports that as of 2004, while 30 states permit such use of Part C funds, only 14 states have adopted such a policy.

In addition to citing delays, state and local officials cited other obstacles to a smooth transition for children. Local early intervention programs sometimes have to work with multiple LEAs that each have their own eligibility criteria for Part B, which complicates coordination. For example, a local Massachusetts official said that her early intervention program spans a geographical area that encompasses 13 different LEAs. Also, LEAs sometimes conduct their own evaluations, contributing to the time needed for determining Part B eligibility.

State and local officials also reported that early intervention programs often do not get final notification of a child's eligibility for Part B services from the LEA. According to OSEP, this information exchange may not occur for several reasons, including federal laws relating to privacy and 
the need for parental consent to share results of Part B evaluations. Without access to information on eligibility decisions, early intervention staff do not know whether they need to refer children who are denied Part B services to other follow-on programs, like Head Start. State Part C officials are required to report Part B eligibility information to OSEP when reporting why a child stopped receiving services, but LEAs that administer Part B do not always provide this information in a timely manner, if at all. While two of the states we visited are in the process of developing mechanisms for ensuring early intervention staff have access to eligibility information, none are currently in use. ${ }^{8}$ OSEP staff acknowledged that states need continued support to ensure Part B officials share eligibility information with early intervention staff.

\section{Conclusions}

Scientific research suggests that the earlier a child with disabilities gets intervention services, the more effective these services may be in enhancing a child's development. Before a child enters preschool, states have substantially greater flexibility in determining which infants and toddlers to serve. IDEA gives states the freedom to set different eligibility criteria for early intervention services and decide how they will evaluate children for eligibility. However, it is partly these variations that make it difficult to determine if states are actually meeting the early intervention needs of all their developmentally delayed infants and toddlers.

One of the most pressing challenges is transitioning young children with disabilities from services provided under IDEA Part C to Part B preschool or other services at age 3 . This transition requires that a sequence of determinations and agreements among multiple stakeholders take place in a timely way. Education reported in its comment that it has preliminary data that suggest that service gaps may occur whenever children transition. In our interviews with state and early intervention officials, we found that transition is perhaps most challenging for children who transition during the summer months. If determination of eligibility for Part B is delayed, children can be prevented from receiving necessary services, including those provided through extended school year programs in the summer. Based on our findings, and Education's preliminary findings from its ongoing study of preschool services, it appears that

\footnotetext{
${ }^{8}$ The most recent reauthorization of IDEA in 2004 includes a provision for the local educational agency under Part B to invite, at the request of the parent, the Part C coordinator or other Part $\mathrm{C}$ representative to the child's initial individualized education plan meeting.
} 
without additional guidance, some children exiting the Part $\mathrm{C}$ program and eligible for Part B preschool may not receive all the services for which they are eligible.

\section{Recommendations for Executive Action}

In order to assist states in providing a more seamless transition for children with disabilities from IDEA Part C to Part B, or other preschool programs, we are recommending that the Secretary of Education provide states with additional guidance on transition planning and services for children with birthdays during the summer, and especially in cases where children are likely to need extended school year services. Additionally, after Education completes and verifies the results from its ongoing studies relating to transitioning, that information should be used to inform the department's guidance to states on transition planning.

\section{Agency Comments and Our Evaluation}

We provided a draft of this report to Education for review and comment. Education disagreed with the recommendation we made to incorporate into its research agenda a method for determining how frequently children transitioning from Part $\mathrm{C}$ to Part $\mathrm{B}$ do not receive services during the summer months, and if gaps in services are found to be a problem, provide states with additional guidance on improving children's access to extended school year services. Education noted that preliminary and unpublished data from a department study indicate that gaps occur when children are transitioned from Part $\mathrm{C}$ to Part B, not only during the summer, but whenever transitions occur. Additionally, Education stated that based on its preliminary data, there is no need to study extended school year service. We believe it is critical to provide children with the services they need when they need them. If Part B eligibility is not determined prior to children turning 3 during the summer months, then related decisions, including those about extended school year services, cannot be made. We believe that by providing additional guidance, Education can help states improve transition planning and services and help ensure that children do not experience gaps in services during critical periods of their development.

Education also provided technical comments that we incorporated into the report where appropriate. Education's written comments are reproduced in appendix II. 
We will send copies of this report to the Secretary of Education, appropriate congressional committees, and others who are interested. We will also make copies available to others upon request. In addition, the report will be available at no charge on GAO's Web site at http://www.gao.gov. If you have any questions about this report, please call me at (202) 512-7215. Key contributors are listed in appendix III.

Sincerely yours,



Marnie S. Shaul, Director

Education, Workforce, and

Income Security Issues 


\section{Appendix I: Select Federal and State Funding Sources for Early Intervention Services}

The Child Care and Development Block Grant program is a discretionary fund program that, among other things, supports state efforts to provide child care to parents trying to achieve independence from public assistance.

Children with Special Health Care Needs refers to a type of program operated by particular states that provides financial assistance or case management for needed medical treatment to children with serious and chronic medical conditions to reduce complications and promote maximum quality of life.

Developmental Disabilities Services refers to state programs that serve and support individuals with mental retardation/developmental disabilities and their families, including early intervention services. For example, community developmental disability services are supported by state funding in Kansas, which defines community developmental disability services as those designed to meet needs associated with work, living in the community, and individualized supports and services.

Head Start and Early Head Start are comprehensive child development programs that serve children from birth to age 5, pregnant women, and their families. These programs are federally funded and locally administered by community-based nonprofit organizations and school systems. Grants are awarded by the Department of Health and Human Services.

IDEA Part B, administered by the Department of Education, provides grants to states to provide preschool services to children with disabilities from age 3 to 5 .

The Maternal and Child Health Services Block Grant program (Title V of the Social Security Act) provides federal grants to states and organizations with the aim of improving the health of mothers and children. Among the many services supported by grants are support programs for children with special health needs, care coordination, transportation, home visiting, and nutrition counseling.

Medicaid is health insurance that helps people who cannot afford medical care pay for some or all of their medical bills. Medicaid is jointly funded by the federal and state governments to assist states in furnishing medical assistance to eligible needy persons. 

funds to states to support a wide variety of social services programs for adults and children.

Temporary Assistance for Needy Families (TANF) is a family assistance block grant from the Department of Health and Human Services to states that can be used to provide monthly cash assistance payments to families as well as to finance services for TANF clients or other lowincome people to support their efforts to work.

Tobacco Funds were awarded to states as part of a settlement agreement with major tobacco companies. Kentucky designated 25 percent of its Phase I settlement to an early childhood initiative that includes First Steps, its early intervention system. Kansas allocated all of its settlement for children's services.

TRICARE is the Department of Defense's regional managed-care program for delivering health care to members of the armed services and their families, survivors, and retired members and their families. TRICARE operates like health maintenance organization plans offered in the private sector and other similar health insurance programs. 


\title{
Appendix II: Comments from the Department of Education
}

\author{
UNITED STATES DEPARTMENT OF EDUCATION \\ OFFICE OF SPECIAL EDUCATION AND REHABILITATIVE SERVICES \\ NOV 142005 \\ THE ASSISTANT SECRETARY
}

Ms. Marnie S. Shaul

Director, Education, Workforce and

Income Security Issues

Government Accountability Office

441 G. Street, NW

Washington, DC 20548

Dear Ms. Shaul:

Thank you for the opportunity to review the draft report entitled: "INDIVIDUALS WITH

DISABILITIES EDUCATION ACT, Study of Service Gaps Could Help Education Guide States in Smoothly Transitioning Children to Preschool" (GAO-06-26). I am pleased to respond on behalf of the Department of Education (Department).

The draft report identifies transition of children with disabilities from early intervention services under Part C of the Individuals with Disabilities Education Act (IDEA) (for children birth to age three) to preschool services under Part B of the IDEA (for children ages three through five) as an area of concern. The Department recognizes that transition is a long-standing challenge for Lead Agencies under Part C and State Education Agencies under Part B with respect to ensuring that children with disabilities who are eligible for preschool services under Part B at age three are identified, evaluated and provided services under Part B in a timely manner. However, preliminary data from a Department-funded study (described below) indicate that the service gap is specific to transition whenever that transition occurs and not, as suggested by the draft report, specific to summer months.

The Office of Special Education Programs (OSEP) has funded a number of projects in this area, most notably the "National Early Childhood Transition Center" (NECTC), which is in its third year at the University of Kentucky. The Center's URL is: http://www.ihdi.uky.edu/nectc/. The Center is looking at all transitions that children and families experience while receiving Part $\mathrm{C}$ early intervention services and Part B preschool services. While the project is still gathering data, results thus far indicate that transition time is reduced for children when staff in both programs formally recognize and plan for the actual time needed to accomplish the logistics of transition. In addition, an important factor is the nature of contacts, i.e., the working relationships between Part $\mathrm{C}$ early intervention service providers and Part B preschool providers at the local level.

The Pre-Elementary Education Longitudinal Study (PEELS), which was initially funded by OSEP and is now housed at the Department's Institute of Education Sciences, is examining the preschool and early elementary school experiences of children with disabilities and the outcomes they achieve. The study is following a nationally representative sample of almost 3,000 children and includes transition issues. The preliminary first wave of data from the PEELS indicates that there are gaps between Part C and Part B preschool services for approximately $30 \%$ of children, according to parent reports. For children who are eligible for Part B preschool services the gap in services averages five

400 MARYLAND AVE., S.W., WASHINGTON, D.C. 20202-2500 www.ed.gov

Our mission is to ensure equal access to education and to promote educational excellence throughout the nation. 
months. Further study will be conducted through PEELS to verify these data.

The draft report recommends that the Department "incorporate into its research agenda a method for determining how frequently children transitioning from Part C to Part B preschool experience service gaps, and if gaps in service are found to be a problem, provide states with additional guidance on extended school year services" (emphasis added). As noted above, the PEELS funded by the Department is already examining the issue of gaps in service delivery between Part C and Part B preschool. At this point, the study has found no correlation between birthdates and particular months of service gaps. That is, spring or summer birthdates are no more likely to lead to gaps in services than fall or winter birthdates. Therefore, the draft report's recommendation regarding the need for studying extended school year (ESY) services seems inapposite, particularly when under Part B ESY services must be provided only if a child's individualized education program (IEP) team determines, on an individual basis, that the services are necessary for the provision of a free appropriate public education (FAPE) to the child.

In addition, the draft report may confuse readers in implying that Parts $\mathrm{C}$ and $\mathrm{B}$ of the IDEA have similar eligibility and service provision requirements. We recommend that the draft report include the following language both in the transition section at page 26 and in the Results in Brief section to clarify these requirements. Some children exiting Part $\mathrm{C}$ may not be eligible for services under Part B. From birth to age three, a child is eligible for early intervention services under Part $\mathrm{C}$ because of established conditions or concerns about the child's exhibiting developmental delay. By contrast, a child with a disability at age three is eligible for preschool services under Part B when the child meets particular disability criteria or, at the option of State and local educational agencies, the child exhibits developmental delay. In most cases, the developmental delay definition for Part B is different from the Part $\mathrm{C}$ developmental delay definition.

As noted earlier, the OSEP-supported National Early Childhood Transition Center is examining factors associated with and contributing to timely and effective transitions. The work of this Center will assist States in putting procedures and practices in place to reduce gaps in services for children who are leaving Part $\mathrm{C}$ and eligible for Part B preschool services.

As is customary, we are providing suggested technical and production edits separately. Please note that many of the technical edits are necessary to ensure the accuracy of the requirements under Parts $B$ and $C$ of the IDEA. We are available to discuss any of our suggested changes with your staff if this would be helpful.



Enclosure 


\section{Appendix III: GAO Contact and Staff Acknowledgments}

\section{GAO Contact}

Staff

Acknowledgments
Marnie S. Shaul (202) 512-7215 or shaulm@gao.gov

In addition to the contact named above, the following individuals made important contributions to this report: Betty Ward-Zukerman, Assistant Director; Ramona Burton, Analyst-in-Charge; Daniele Schiffman, Analyst; Rachael Chamberlin; Sherri Doughty; Avrum Ashery; Jonathan McMurray; Beverly Ross; and Daniel Schwimer. 
The Government Accountability Office, the audit, evaluation and investigative arm of Congress, exists to support Congress in meeting its constitutional responsibilities and to help improve the performance and accountability of the federal government for the American people. GAO examines the use of public funds; evaluates federal programs and policies; and provides analyses, recommendations, and other assistance to help Congress make informed oversight, policy, and funding decisions. GAO's commitment to good government is reflected in its core values of accountability, integrity, and reliability.

Obtaining Copies of GAO Reports and Testimony

\section{Order by Mail or Phone}

The fastest and easiest way to obtain copies of GAO documents at no cost is through GAO's Web site (www.gao.gov). Each weekday, GAO posts newly released reports, testimony, and correspondence on its Web site. To have GAO e-mail you a list of newly posted products every afternoon, go to www.gao.gov and select "Subscribe to Updates."

The first copy of each printed report is free. Additional copies are $\$ 2$ each. A check or money order should be made out to the Superintendent of Documents. GAO also accepts VISA and Mastercard. Orders for 100 or more copies mailed to a single address are discounted 25 percent. Orders should be sent to:

U.S. Government Accountability Office

441 G Street NW, Room LM

Washington, D.C. 20548

To order by Phone: Voice: (202) 512-6000

TDD: (202) 512-2537

Fax: (202) 512-6061

\section{To Report Fraud, Waste, and Abuse in Federal Programs}

\section{Contact:}

Web site: www.gao.gov/fraudnet/fraudnet.htm

E-mail: fraudnet@gao.gov

Automated answering system: (800) 424-5454 or (202) 512-7470

Gloria Jarmon, Managing Director, JarmonG@gao.gov (202) 512-4400 U.S. Government Accountability Office, 441 G Street NW, Room 7125 Washington, D.C. 20548 